\title{
Spor Bilimleri Alanında Eğitim Gören Üniversite Öğrencilerinin Sportmenlik Davranışları ile Saygı Düzeyleri Arasındaki İlişkinin İncelenmesi*
}

\author{
Relationship between Sportsmanship Behaviors and Respect Levels of \\ University Students in Sport Sciences
}

\author{
ORIJINAL ARAŞTIRMA/ \\ ORIGINAL RESEARCH \\ Yakup $\mathrm{KOÇ}^{\mathbf{1}}$ \\ Emrah SEÇER ${ }^{2}$ \\ ${ }^{\mathbf{1} E r z i n c a n}$ Binali Yıldırım \\ Üniversitesi, Erzincan, \\ https://orcid.org/0000-0003-0141- \\ 7177 \\ ${ }^{2}$ Erzincan Binali Yıldırım \\ Üniversitesi, Erzincan, \\ https://orcid.org/ 0000-0002-6683- \\ $680 \mathrm{X}$
}

\section{Yayın Bilgisi}

Gönderi Tarihi: 24.01.2018

Kabul Tarihi: 20.12.2018

Online Yayın Tarihi: 31.12.2018

\begin{abstract}
$\ddot{O} \mathbf{z}$
$\mathrm{Bu}$ araştırmanın amacı; spor bilimleri alanında eğitim gören üniversite öğrencilerinin sportmenlik davranışları ile saygı düzeyleri arasındaki ilişkiyi incelemektir. Araştırma grubunu 2016-2017 eğitim-öğretim y1lında spor bilimleri alanında öğrenimlerine devam eden 302 üniversite öğrencisi oluşturmuştur. Araştırmada Koç (2013) tarafından geliştirilen "Beden Eğitimi Dersi Sportmenlik Ölçeği (BEDSÖ)" ile Yazıcı \& Yazıcı (2015) tarafından geliştirilen "Saygı Ölçeği" ve araştırmacı tarafindan oluşturulan kişisel bilgi formu kullanılmıştır. Öğrencilerin ölçeklerden aldığı puanlar bağımsız değişkenlere göre incelenmiştir. Ayrıca öğrencilerin sportmenlik değerleriyle saygı düzeyleri arasındaki ilişkiye (Pearson) bakılmıştır. Ölçeklerin üniversite öğrencileri için geçerli ve güvenilir ölçekler olduğu anlaşılmıştır. Öğrencilerin sportmenlik davranışlarının ve saygı düzeylerinin cinsiyetlerine (kadınlar lehine) ve sinıf düzeylerine ( 1 ve 4 . sinıflar lehine) göre bazı boyutlarda anlamlı düzeyde farklılaştığı görülmüştür. Ölç̧ek puanlarının ögrencilerin üniversite takımlarında oynamalarına, aktif spor yapmalarına ve yaptıkları branş türlerine göre anlamlı düzeyde farklılaşmadığ 1 görülmüştür. Öğrencilerin sportmenlik davranışlarıyla saygı düzeyleri arasında pozitif yönde anlamlı ilişki bulunmuştur. Üniversitede öğrencilerin saygı düzeylerini geliştirmeye yönelik etkinlikler uygulamanın öğrencilerin sportmenlik davranışlarını geliştirmede faydalı olacağı düşünülmektedir.
\end{abstract}

Anahtar Kelimeler: Spor bilimleri, sportmenlik davranışı, saygı düzeyi, fair play

\begin{abstract}
The purpose of this study is to examine relationship between sportsmanship behaviors and respect levels of university students in sport sciences. The research group consisted of 302 university students who continued their education in sport sciences in 2016-2017 academic year. "Physical Education Course Sportspersonship Behavior Scale" (PECSBS) developed by Koç (2013), "Respect Scale" developed by Yazıc1 \& Yazıc1 (2015) and personal information form created by the researcher were utilized in the study. The scores obtained by the students from the scales were examined according to the independent variables. In addition, the relationship between sportsmanship values and respect levels for the students was examined (Pearson). It was found that the scales was valid and reliable and could be used for university students. Sportsmanship behaviors and respect levels significantly differed according to the gender of the students (in favor of the girls) and the grade (in favor of $1^{\text {st }}$ and $4^{\text {th }}$ grades). It was understood that the scale scores of the students are not significantly different according to playing in university teams, actively doing sports and the type of sports. It was found total sportsmanship behaviors are significantly related to total respect levels positively. It is believed that the implementation of activities aimed at improving the level of respect of students in university will be helpful in improving sportsmanship behaviors of students.
\end{abstract}

Keywords: Sport sciences, sportsmanship behavior, level of respect, fair play

\footnotetext{
* Bu çalışma, Uluslararası 9. Beden Eğitimi ve Spor Öğretmenliği Kongresi’nde (19-22 Ekim 2017) aynı adla sözlü bildiri olarak sunulmuştur.

†Sorumlu yazar: Yakup Koç, ykoc79@gmail.com
} 


\section{GİRIŞ̧}

Sportmenlik kavramı tanımlarına bakıldığında insan onuruna gösterilen saygının ifadesi olarak ortaya çıkmış, beden eğitimi ve sporun her aşamasında ve her türünde hakça ve dürüstçe oyun oynama olarak kendini kabul ettirmiş̧tir (Pehlivan, 2004). Sportmenlik, spor geleneğinin bir parçasıdır. Sporda sık sık referansın yapılan bir terim olmasına karşın tanımlamadan ziyade içeriği ile ilgili kısa açıklamalar verilmektedir. Sportmenlik ve onun spor ve ahlak ile ilişkisi yaygın olarak varsayılsa da karmaşık yapısı nedeniyle tanımlama yapılması pek tercih edilmemektedir (Arnold, 1998). Spor ortamında ahlaki idealleri ifade etmek için kullanılan sportmenlik kavramı için farklı bakış açılarıyla değişik tanımlamalar yapılmıştır. Shields \& Bredemeier, (1995), sportmenliği ahlaki hedeflerin 1şığında rekabetçi oyun dürtüsünü düzenleme erdemi olarak tanımlar. Keating (2007), sportmenliğin doğruluk, sabır, öz kontrol, öz saygı, adalet, bağışlama, büyüklük ve nezaket gibi özellikleri içerdiğini vurgulamıştır. Başka bir kaynakta sportmenlik, spor ve aktiviteyi adalet, ahlak, saygı ve arkadaşlık gibi uygun davranışlarla güzelleştirme istek ve kültürü olarak tanımlanmıştır (Ellis, Henderson, Paisley, Silverberg \& Wells, 2004).

Beden eğitimi ve spor faaliyetlerinde sportmenlik davranışının daha iyi anlaşılarak içeriğinin net olarak ortaya konması sportmenlik davranışını geliştirmeye yönelik programlara yol gösterecektir. Literatüre bakıldığında sportmenliğin bazı kişilik özellikleri ile ilişkili olduğu tespit edilmiştir. Sportmenliğin empati (Balçıkanlı \& Yıldıran, 2011; Koç, 2017b), sabır (Koç, 2017a), şiddet eğilimi (Koç, 2017b), saldırganlık (Koç \& Güllü, 2017), gibi kişilik özellikleri ile yakın iliş̧ili olduğu ortaya konmuştur. Sportmenlik kavramı ne kadar iyi anlaşılırsa sportmenliği geliştirici uygulamalar da o kadar etkili olacaktır. Bu açıdan sportmenlik tüm yönleriyle ele alınmalı ve kuramsal çalışmalar çoğaltılmalıdır.

Sportmenliğin kişilik özelliklerinden saygı davranışı ile ne derece ilişkili olduğu yeterince araştırılmadığı görülmüştür. Oysa spor sahalarında sportmenlik ve Fair play’e yönelik materyallere bakıldığında bireyin sayg1 davranışına vurgu yapıldığı görülmektedir. $\mathrm{Bu}$ kavramların tanımlarında da bireyin saygı davranışına atıfta bulunulmaktadır. Örneğin; Valerand ve arkadaşları geliştirdikleri ve Türkçe'ye de çevrilen sportmenlik yönelimi ölçeğinde sportmenliğin 6 boyuttan 4'ünü "saygı" adıyla nitelendirmiştir (Vallerand, Briere, Blanchard \& Provencher, 1997). Diğer taraftan FiFA'da resmi kampanyalarında Fair play ile saygı kavramını (respect) beraber kullanmaktadır (www.fifa.com, 2017). 
Sözlükler saygı ile ilgili sayısız sayıda tanımlamalar yapmaktadır (Hendrick, Hendrick, \& Zacchilli, 2011). Sayg1, sadece temel değerlerden biri değil, aynı zamanda birçok değerin de temelidir (Loomans \& Loomans, 2005). Saygı, insanın kendi kişiliğiyle başkalarının kişiliğinin arasındaki sınırı bilip o sınırı aşmaması, kendi aleyhine dahi olsa başkasının hakkına, hukukuna özen göstermesidir (Demircan, 2017). Literatürde saygıyı kuramsal olarak inceleyen az da olsa bazı çalışmalar mevcuttur. Bu çalışmalardan birinde Yazıcı \& Yazıcı (2015), saygının evrensel değerlerin anlaşıldığı kozmopolitan saygı ve yerel değerlerin vurgulandığı komüniteryan saygı olarak iki boyuttan oluştuğunu öne sürerek aynı adlardan oluşan iki boyutlu saygı ölçeği geliştirmişlerdir. Evrenselci (cosmopolitan) ve cemaatçi (communitarian) düşünme biçimleri son otuz yıl ahlak ve siyaset felsefesi literatüründe yer alan iki yaklaşımdır. Evrensel düşünme tarzı ifade özgürlüğünü savunarak, insanlar arasında her türlü eşitliği benimseyerek, cezaya taraf değildir. Demokratik ve eşitlikçi yaşam anlayışını önemsemektedir. Yerel düşünce tarzı ise insanlar açısından kurtuluşu ve çareleri, kendi toplumu içerisinde arayarak topluma ait olan her şeye önem verir (Türk, 2009).

Sportmenlik ve fair-play alanında yapılan çalışmalarda doğrudan sportmenlik ve saygı davranışları arasındaki ilişkinin boyutunu araştıran bir çalışmaya Koç ve Yeniçeri'nin (2017) lise öğrencileri üzerinde yaptığı çalışma haricinde rastlanılmamıştır. Dolayısıyla sportmenlik ile saygı arasındaki ilişki düzeyinin incelenmesine daha fazla ihtiyaç olduğu düşünülmektedir.

Spor bilimleri alanında eğitim gören üniversite öğrencilerinde kullanılabilecek sportmenlik ölçeği bulunmaması eksiklik olduğu düşünülmektedir. Özellikle spor bilimleri eğitimi alan lisans öğrencileri için uygulanacak etkinliklerde sportmenlik ile ilişkili kişilik özelliklerinin bilinmesi etkinliklerin başarı şansını arttıracaktır. Ayrıca sportmenlik ölçeğinin üniversitede okuyan spor bilimleri öğrencileri için de kullanılabilirliğinin anlaşılması, ölçeğin sportmenlik davranışı ile ilgili araştırmalarda kullanılabilmesini sağlayacaktır.

Bu araştırmanın ana amacı; spor bilimleri alanında eğitim gören üniversite öğrencilerinin sportmenlik davranışları ile saygı düzeyleri arasındaki ilişkiyi incelemek ve öğrencilerin saygı seviyesinin öğrencilerin sportmenlik davranışlarını ne ölçüde yordadığını ortaya koymaktır. Ayrıca araştırmanın alt amaçlarını öğrencilerin ölçeklerden aldığı puanların bağımsız değişkenlere göre (cinsiyet, sınıf, üniversite takımlarında oynama, aktif spor yapma ve yapılan branş türü) incelenmesi oluşturmuşstur. 


\section{YÖNTEM}

\section{Araştırma Modeli}

Araştırmada nicel araştırma modellerinden ilişkisel tarama yöntemi kullanılmıştır. Bu yöntem iki ve daha fazla değişken arasında birlikte ortaya çıkan değişimi ve/veya derecesini tespit etmeyi hedefleyen araştırma yöntemidir (Karasar, 2003).

\section{Çalışma Grubu}

Araştırma grubunu 2016-2017 eğitim-öğretim yılında spor bilimleri alanında 2 farklı üniversitede (Erzincan Üniversitesi ve Karadeniz Teknik Üniversitesi) öğrenimlerine devam eden ve seçkisiz örneklem yoluyla seçilen 302 üniversite öğrencisi (97 kadın, 205 erkek) oluşturmuştur.

\section{Veri Toplama Aracı}

Araştırmada "Beden Eğitimi Dersi Sportmenlik Davranışı Ölçeği (BEDSDÖ)”, "Sayg1 Ölçeği” ve araştırmacı tarafından oluşturulan kişisel bilgi formu kullanılmıştır.

Beden Eğitimi Dersi Sportmenlik Davranışı Ölçeği (BEDSDÖ): Koç, (2013) tarafından geliştirilen beden eğitimi dersi sportmenlik davranışı ölçeği 5'li Likert tipi ölçektir. Orijinal ölçek 11 madde "Pozitif Davranışlar Sergileme" (PDS) faktörü (madde 1, 2, 4, 7, 9, 11, 12, 14, 16, 19 ve 21 ) ve ters puanlanan 11 madde "Negatif Davranışlardan Kaçınma” (NDK) faktörü (madde 3, $5,6,8,10,13,15,17,18,20$ ve 22) olmak üzere toplam 22 maddeden oluşmaktadır. PDS Faktörüne "Beden eğitimi dersinde oyunda rakibim düşerse kalkmasına yardım ederim" ve NDK Faktörüne "Beden eğitimi dersinde yendiğim zaman karşı takımın oyuncusuyla dalga geçerim" maddeleri örnek olarak verilebilir. Çalışma spor bilimlerinde okuyan öğrencilere uygulandığı için maddelerin başında yer alan "Beden eğitimi dersinde" ibaresi yerine "Uygulama derslerinde" ifadesi kullanılmıştır. Ölçeğin dereceleme biçimi maddelerde yer alan davranışların sergilenme sıklığını ölçmeye yönelik olarak hazırlanmıştır. Ölçek maddelerine verilebilecek cevaplar “(5) Her Zaman, (4) Çok Sık, (3) Ara Sıra, (2) Nadiren ve (1) Hiçbir Zaman” şeklinde sıralanmıştır. Ölçeğin toplamından elde edilen puan "Toplam Sportmenlik (TS)" olarak değerlendirilmektedir. Ölçekten alınabilecek en düşük puan 22 (ortalama 1) ve en yüksek puan 110 (ortalama 5) dur. Faktör 1 ve Faktör 2 den ayrı ayrı olarak alınabilecek puanlar en düşük 11 (ortalama 1) ve en yüksek 55 
(ortalama 5) dir. Ölçekten alınan puanlar arttıkça öğrencilerin sportmenlik düzeylerinin daha iyi olduğu anlaşılmaktadır.

Ölçeğin daha önce üniversite öğrencilerinde kullanılmadığı göze alınarak öncelikle alanında uzman öğretim üyelerince ön incelenme yapılmıştır. Sonraki aşamada ölçek 20 Spor bilimleri öğrencisiyle yapılan ön uygulamaların değerlendirilmesinden sonra çalışmada kullanılmıştır. Ve çalışma grubunda sportmenlik ölçeği için Doğrulayıcı Faktör Analizi (DFA) yapılmıştır. Yapılan analiz sonucunda uyum indekslerinin iyi ve kabul edilebilir sınırlar içerisinde olduğu anlaşılmıştır $\left(\chi^{2} / \mathrm{df}=2.16\right.$, RMSEA=.062, $\mathrm{CFI}=.95, \mathrm{NNFI}=.94$ ve AGFI=.85). Ayrıca sportmenlik ölçeğin iç tutarlılık güvenirliği (Cronbach Alpha) NDK faktörü için 0.86, PDS faktörü için 0.81 ve tüm ölçek için 0.84 olarak hesaplanmıştır.

Saygı Ölçeği: Yazıcı \& Yazıcı (2015) tarafından geliştirilen Saygı Ölçeği 5'li Likert tipi ölçektir. Ölçek 9 madde "Kozmopolitan Saygı" faktörü (maddeler 1-9) ve 8 madde “Komüniteryan Saygı” faktörü (maddeler 10-17) olmak üzere toplam 17 maddeden oluşmaktadır. Kozmopolitan Saygı faktörüne "İnsanları birbirinden ayırmadan saygı göstermeliyiz" maddesi ve Komüniteryan Saygı faktörüne de "Yakın çevremizdeki insanlara karşı saygılı olmada özel önem göstermeliyiz" maddesi örnek gösterilebilir. Ölçeğin toplamından elde edilen puan "Toplam Saygı" olarak değerlendirilmektedir. Ölçekten alınan puanlar arttıkça öğrencilerin saygı düzeylerinin daha iyi olduğu anlaşılmaktadır. Çalışma grubunda saygı ölçeğinin geçerliliğini test etmek için de DFA yapılmıştır. Yapılan analiz sonucunda uyum indekslerinin büyük oranda kabul edilebilir sınırlar içerisinde olduğu anlaşılmıştır $\left(\chi^{2} / \mathrm{df}=2.95, \mathrm{RMSEA}=.08, \mathrm{CFI}=.90, \mathrm{NNFI}=.88\right.$ ve AGFI=.85). Saygı Ölçeği'nin iç tutarlılık güvenirliği (Cronbach Alpha) Kozmopolitan Sayg1 faktörü için 0.81 , Komüniteryan Saygı faktörü için 0.72 ve tüm ölçek için 0.79 olduğu hesaplanmıştır. Ölçeğin toplamından elde edilen puan "Toplam Sayg1 (TS)" olarak değerlendirilmektedir. Veriler doğrultusunda çalışmada kullanılan ölçeklerin üniversite öğrencileri için geçerli ve güvenilir ölçekler olduğu anlaşılmıştır.

\section{Verilerin Analizi}

Ölçeklerin geçerliliği (doğrulayıcı faktör analizi) ve güvenirliği (Cronbach Alpha) test edilmiştir. Ölçek puanların çarpıklık ve basıklık değerlerine bakılarak normallik sınaması yapılmıştır. Öğrencilerin ölçeklerden aldığı puanlar bağımsız değişkenlere göre incelenmiştir. Verilerin analizinde tanımlayıcı istatistiksel teknikler, ikili grup karşılaştırmalarında Indepenent 
Sample t, çoklu grup karşılaştırmalarında ise One-Way ANOVA ile birlikte Tukey HSD testleri yapılmıştır. Öğrencilerin sportmenlik değerleriyle saygı düzeyleri arasındaki ilişkiye (Pearson) bakılmıştır. Ölçekler değerlerinin normal dağılım göstermesi ve ölçekler arasında doğrusal ilişki görüldüğünden saygı düzeyinin sportmenlik davranışını ne ölçüde yordadığına (basit doğrusal regresyon analizi) bakılmıştır. Verilerin değerlendirilmesinde SPSS 22 ve LISREL 8.7 programları kullanılmıştır.

\section{BULGULAR}

Tablo 1. Öğrencilerin ölçek puanlarının ortalama, standart sapma, minimum, maksimum, çarpıklık ve basıkl1k değerleri

\begin{tabular}{llllllc}
\hline & $\overline{\boldsymbol{x}}$ & Ss. & Min. & Maks. & Çarpıklık & Basıklık \\
\hline Pozitif Davranışlar Sergileme & 4.05 & .62 & 2.00 & 5.00 & -.53 & -.11 \\
Negatif Davranışlardan Kaçınma & 3.90 & .81 & 1.27 & 5.00 & -1.18 & .93 \\
Toplam Sportmenlik & 3.98 & .59 & 2.48 & 5.00 & -.48 & -.59 \\
Kozmopolitan Saygı & 4.08 & .67 & 1.67 & 5.00 & -.78 & .32 \\
Komüniteryan Saygı & 3.86 & .63 & 2.00 & 5.00 & -.23 & -.41 \\
Toplam Saygı & 3.97 & .51 & 2.40 & 5.00 & -.17 & -.44
\end{tabular}

Tablo 1'de öğrencilerin ölçek puanlarının tanımlayıcı istatistiklerine yer verilmiştir. Tüm ölçek puanlarında çarpıklık ve basıklık katsayılarının -1,5, +1,5 sınırları içerisinde olduğu tespit edilmiştir. Tabachnick ve Fidell (2013), ölçeklerde yer alan ifadelere ilişkin çarpıklık ve basıklık değerlerinin, -1,5- +1,5 değerleri arasında olması durumunda, verinin normal dağılım sergileyeceğini ifade etmektedir. Verilerin karşılaştırılması için parametrik testler kullanılmasının uygun olduğu görülmüştür.

Tablo 2. Öğrencilerin ölçek puanlarının cinsiyetlerine göre karşılaştırılması (t-Test)

\begin{tabular}{lcccccc}
\hline Faktör & Cinsiyet & $\mathbf{N}$ & $\overline{\mathbf{X}}$ & $\mathbf{s s .}$ & $\mathbf{t}$ & $\boldsymbol{p}$ \\
\hline Pozitif Davranışlar Sergileme & Kadın & 97 & 4.04 & .55 & -.23 & .821 \\
Negatif Davranışlardan Kaçınma & Erkek & 205 & 4.06 & .66 & .23 & \\
& Kadın & 97 & 4.09 & .65 & 2.77 & $.006^{* *}$ \\
Toplam Sportmenlik & Erkek & 205 & 3.82 & .86 & & \\
& Kadın & 97 & 4.07 & .47 & 1.77 & .077 \\
Kozmopolitan Saygı & Erkek & 205 & 3.94 & .63 & & \\
Komüniteryan Saygı & Kadın & 97 & 4.23 & .58 & 2.63 & $.009^{* *}$ \\
& Erkek & 205 & 4.01 & .71 & & \\
Toplam Saygı & Kadın & 97 & 3.80 & .66 & -1.24 & .218 \\
& Erkek & 205 & 3.89 & .62 & & .3 \\
\hline
\end{tabular}

$* * \mathrm{p}<0.01$ 
Öğrencilerin sportmenlik davranışlarının ve saygı düzeylerinin cinsiyetlerine göre negatif davranışlardan kaçınma $\left[\mathrm{t}_{(300)}=2.77, \mathrm{p}<0.05\right]$ ve kozmopolitan saygı boyutlarında $\left[\mathrm{t}_{(300)}=2.63\right.$, $\mathrm{p}<0.05]$ anlamlı düzeyde farklılaştı̆̆ görülmüştür. Öğrencilerin negatif davranışlardan kaçınma alt boyutunda kadınların puanları $(\overline{\boldsymbol{x}}=4.09)$ erkeklerin puanlarından $(\overline{\boldsymbol{x}}=3.82)$ anlamlı düzeyde yüksek çıkmıştır. Aynı şekilde kozmopolitan saygı alt boyutunda kadınların puanları $(\overline{\boldsymbol{x}}=4.23)$ erkeklerin puanlarından ( $\overline{\boldsymbol{x}=} 4.01)$ anlamlı düzeyde yüksek çıkmıştır (Tablo 2).

Tablo 3. Öğrencilerin ölçek puanlarının sınıf seviyesine göre karşılaştırılması (One-Way Anova)

\begin{tabular}{lccccccc}
\hline Faktör & Sinıf & $\mathbf{N}$ & $\overline{\mathbf{x}}$ & $\mathbf{S s}$ & $\mathbf{F}$ & $\boldsymbol{p}$ & Tukey T. \\
\hline Pozitif Davranışlar Sergileme & 1 & 132 & 4.13 & .65 & 2.487 & .061 & \\
& 2 & 55 & 4.00 & .61 & & & \\
Negatif Davranışlardan Kaçınma & 3 & 75 & 3.91 & .58 & & & \\
& 4 & 40 & 4.14 & .59 & & & \\
& 1 & 132 & 4.08 & .61 & 11.452 & .000 & $*(1>3)$ \\
Toplam Sportmenlik & 2 & 55 & 3.78 & .91 & & & $*(4>2)$ \\
& 3 & 75 & 3.52 & 1.00 & & & $*(4>3)$ \\
& 4 & 40 & 4.24 & .43 & & & \\
Kozmopolitan Saygı & 1 & 132 & 4.10 & .54 & 10.082 & .000 & $*(1>3)$ \\
& 2 & 55 & 3.89 & .58 & & & $*(4>3)$ \\
Komüniteryan Saygı & 3 & 75 & 3.71 & .65 & & & \\
& 4 & 40 & 4.19 & .43 & & & \\
Toplam Saygı & 1 & 132 & 4.08 & .64 & 1.265 & .286 & \\
& 2 & 55 & 4.18 & .71 & & & \\
& 3 & 75 & 3.97 & .70 & & & \\
& 4 & 40 & 4.15 & .69 & & & \\
& 1 & 132 & 3.75 & .66 & 2.930 & .034 & \\
& 2 & 55 & 3.93 & .60 & & & \\
& 3 & 75 & 3.92 & .53 & & & \\
& 4 & 40 & 4.04 & .72 & & & \\
& 1 & 132 & 3.92 & .51 & 1.935 & .124 & \\
& 2 & 55 & 4.06 & 49 & & &
\end{tabular}

$* \mathrm{p}<0.05 \quad * * \mathrm{p}<0.01$

Öğrencilerin sportmenlik davranışlarının ve saygı düzeylerinin sınıf düzeylerine göre negatif davranışlardan kaçınma $\left[\mathrm{F}_{(3-298)}=11.45, \mathrm{p}<0.05\right]$ ve toplam sportmenlik puanlarında $\left[\mathrm{F}_{(3-298)}=\right.$ 10.02, $\mathrm{p}<0.05]$ anlamlı düzeyde farklılaştı̆̆ görülmüştür. Negatif davranışlardan kaçınma alt boyutunda 1. $\operatorname{sinıf}(\overline{\boldsymbol{x}}=4.08)$ ve $4 . \operatorname{sinıf}(\overline{\boldsymbol{x}}=4.24)$ öğrencilerinin ortalamalarının $2 . \operatorname{sinıf}(\overline{\boldsymbol{x}}=3.78)$ ve 3. sinıflara $(\overline{x=3.52)}$ göre anlamlı olarak yüksek olduğu görülmüştür. Aynı şekilde Toplam Sportmenlik davranışlarında da 1. sınıf $(\bar{x}=4.10)$ ve 4 . sınıf $(\overline{x=} 4.19)$ öğrencilerinin ortalamaları 2. $\operatorname{sinıf}(\overline{\boldsymbol{x}}=3.89)$ ve 3 . sinıflara $(\overline{\boldsymbol{x}}=3.71)$ göre anlamlı olarak yüksek olduğu görülmüsstür (Tablo $3)$. 
Koç, Y. ve Seçer, E. (2018). Spor bilimleri alanında eğitim gören üniversite öğrencilerinin sportmenlik davranışları ile saygı düzeyleri arasındaki ilişkinin incelenmesi. CBÜ Beden Ĕ̆itimi ve Spor Bilimleri Dergisi, 13(2), 247-259.

Tablo 4. Öğrencilerin ölçek puanlarının üniversite takımlarında görev almalarına göre karşılaştırılması (tTest)

\begin{tabular}{|c|c|c|c|c|c|c|}
\hline Faktör & Grup & $\mathbf{N}$ & $\overline{\mathbf{x}}$ & sS & $\mathbf{t}$ & $p$ \\
\hline \multirow[t]{2}{*}{ Pozitif Davranışlar Sergileme } & Evet & 111 & 4.11 & .59 & \multirow{2}{*}{1.14} & \multirow{2}{*}{.257} \\
\hline & Hayır & 191 & 4.02 & .64 & & \\
\hline \multirow[t]{2}{*}{ Negatif Davranışlardan Kaçınma } & Evet & 111 & 3.87 & .82 & \multirow{2}{*}{-.58} & \multirow{2}{*}{.561} \\
\hline & Hayır & 191 & 3.92 & .81 & & \\
\hline \multirow[t]{2}{*}{ Toplam Sportmenlik } & Evet & 111 & 3.99 & .60 & \multirow{2}{*}{.20} & \multirow{2}{*}{.840} \\
\hline & Hayır & 191 & 3.97 & .58 & & \\
\hline \multirow[t]{2}{*}{ Kozmopolitan Saygı } & Evet & 111 & 4.02 & .74 & \multirow{2}{*}{-1.21} & \multirow{2}{*}{.226} \\
\hline & Hayır & 191 & 4.12 & .64 & & \\
\hline \multirow[t]{2}{*}{ Komüniteryan Saygı } & Evet & 111 & 3.90 & .60 & \multirow{2}{*}{.75} & \multirow{2}{*}{.456} \\
\hline & Hayır & 191 & 3.84 & .65 & & \\
\hline \multirow[t]{2}{*}{ Toplam Saygı } & Evet & 111 & 3.96 & .54 & \multirow{2}{*}{-.34} & \multirow{2}{*}{.735} \\
\hline & Hayır & 191 & 3.98 & .50 & & \\
\hline
\end{tabular}

Ölçek puanlarının öğrencilerin üniversite takımlarında görev almalarına göre anlamlı düzeyde farklılaşmadığı görülmüştür ( $\mathrm{p}>0.05$ ) (Tablo 4).

Tablo 5. Öğrencilerin ölçek puanlarının aktif spor yapmalarına göre karşılaştırılması (t-Test)

\begin{tabular}{lcccccc}
\hline Faktör & Grup & $\mathbf{N}$ & $\overline{\mathbf{X}}$ & $\mathbf{s d}$ & $\mathbf{t}$ & $\boldsymbol{p}$ \\
\hline Pozitif Davranışlar Sergileme & Evet & 185 & 4.11 & .62 & \multirow{2}{*}{. } & \\
Negatif Davranışlardan Kaçınma & Hayır & 117 & 3.97 & .63 & 1.89 & .060 \\
Toplam Sportmenlik & Evet & 185 & 3.89 & .81 & & \\
& Hayır & 117 & 3.92 & .81 & -.24 & .812 \\
Kozmopolitan Saygı & Evet & 185 & 4.00 & .59 & & \\
& Hayır & 117 & 3.94 & .59 & .83 & .405 \\
Komüniteryan Saygı & Evet & 185 & 4.04 & .70 & & \\
& Hayır & 117 & 4.15 & .63 & -1.44 & .151 \\
Toplam Saygı & Evet & 185 & 3.90 & .63 & & \\
& Hayır & 117 & 3.80 & .64 & 1.40 & .163 \\
& Evet & 185 & 3.97 & .53 & & \\
\hline
\end{tabular}

Ölçek puanlarının öğrencilerin aktif spor yapmalarına göre anlamlı düzeyde farklılaşmadığı görülmüş̧ür ( $\mathrm{p}>0.05)$ (Tablo 5) 
Koç, Y. ve Seçer, E. (2018). Spor bilimleri alanında eğitim gören üniversite öğrencilerinin sportmenlik davranışları ile saygı düzeyleri arasındaki ilişkinin incelenmesi. CBÜ Beden Eğitimi ve Spor Bilimleri Dergisi, 13(2), 247-259.

Tablo 9. Öğrencilerin ölçek puanlarının yaptıkları branş türlerine göre karşılaştırılması (One-Way Anova)

\begin{tabular}{lcccccc}
\hline Faktör & Grup* & $\mathbf{N}$ & $\overline{\mathbf{X}}$ & Ss. & $\mathbf{F}$ & $\boldsymbol{p}$ \\
\hline Pozitif Davranışlar Sergileme & 1 & 60 & 4.01 & .67 & 1.18 & .308 \\
& 2 & 72 & 4.17 & .61 & & \\
Negatif Davranışlardan Kaçınma & 3 & 53 & 4.13 & .56 & & \\
& 1 & 60 & 3.99 & .75 & .76 & .470 \\
Toplam Sportmenlik & 2 & 72 & 3.81 & .86 & & \\
& 3 & 53 & 3.90 & .82 & & \\
Kozmopolitan Saygı & 1 & 60 & 4.00 & .57 & .02 & .976 \\
& 2 & 72 & 3.99 & .61 & & \\
Komüniteryan Saygı & 3 & 53 & 4.02 & .59 & & \\
& 1 & 60 & 3.95 & .71 & .93 & .398 \\
Toplam Saygı & 2 & 72 & 4.03 & .75 & & \\
& 3 & 53 & 4.13 & .63 & & \\
& 1 & 60 & 3.84 & .60 & 2.61 & .076 \\
& 2 & 72 & 4.03 & .57 & & \\
\end{tabular}

N=185, * (Gruplar: 1= Bireysel mücadele sporu, 2= Topla oynana takım sporu 3= Bedensel temas olmayan spor)

Ölçek puanlarının öğrencilerin yaptıkları branş türlerine göre anlamlı düzeyde farklılaşmadığı görülmüştür ( $\mathrm{p}>0.05$ ) (Tablo 6).

Tablo 7. Öğrencilerin Sportmenlik Davranışlar ile Saygı Düzeyleri Arasındaki Korelasyon Sonuçları (Pearson)

\begin{tabular}{lllllll}
\hline Faktör & $\mathbf{1}$ & $\mathbf{2}$ & $\mathbf{3}$ & $\mathbf{4}$ & $\mathbf{5}$ & $\mathbf{6}$ \\
\hline 1. Pozitif Davranışlar Sergileme & - & $.32^{* *}$ & $.76^{* *}$ & $.28^{* *}$ & $.12^{*}$ & $.26^{* *}$ \\
2. Negatif Davranışlardan Kaçınma & & - & $.87^{* *}$ & $.15^{*}$ & -.03 & .08 \\
3. Toplam Sportmenlik & & & - & $.25^{* *}$ & .04 & $.19^{* *}$ \\
4. Kozmopolitan Saygı & & & & - & $.22^{* *}$ & $.80^{* *}$ \\
5. Komüniteryan Saygı & & & & & - & $.77^{* *}$ \\
6. Toplam Saygı & & & & & & - \\
$\quad \overline{\mathbf{x}}(\mathbf{1 - 5})$ & 4.05 & 3.90 & 3.98 & 7.08 & 3.86 & 3.97 \\
$\quad$ SS. & .62 & .81 & .59 & .67 & .63 & .51 \\
\hline
\end{tabular}

$\mathrm{N}=302, * \mathrm{p}<0.05, * * \mathrm{p}<0.01$

Öğrencilerin toplam sportmenlik davranışlarıyla toplam saygı düzeyleri arasında pozitif yönde zayıf anlamlı ilişki bulunmuştur ( $\mathrm{r}=.19, \mathrm{p}<0.01)$ (Tablo 7). 
Koç, Y. ve Seçer, E. (2018). Spor bilimleri alanında eğitim gören üniversite öğrencilerinin sportmenlik davranışları ile saygı düzeyleri arasındaki ilişkinin incelenmesi. CBÜ Beden Eğitimi ve Spor Bilimleri Dergisi, 13(2), 247-259.

Tablo 8. Öğrencilerin ölçek sonuçlarının basit doğrusal regresyon analizi sonuçları

\begin{tabular}{|c|c|c|c|c|c|c|c|c|c|}
\hline $\begin{array}{l}\text { Pozitif Davranışlar } \\
\text { Sergileme }\end{array}$ & B & $\mathrm{SE}(\mathrm{B})$ & $\beta$ & $t$ & $p$ & $\mathrm{R}^{2}$ & $\begin{array}{l}\text { Düz. } \\
\mathrm{R}^{2}\end{array}$ & $\begin{array}{c}\text { Anova } \\
\mathrm{f}\end{array}$ & $\begin{array}{c}\text { Anova } \\
\mathrm{p}\end{array}$ \\
\hline Kozmopolitan Sayg1 & .260 & .051 & .281 & 5.063 & $.000 * *$ & .079 & .076 & 25.63 & .000 \\
\hline Komüniteryan Sayg1 & .115 & .057 & .116 & 2.027 & $.000 * *$ & .014 & .010 & 4.11 & .044 \\
\hline Toplam Saygi & .314 & .068 & .257 & 4.612 & $.000 * *$ & .066 & .063 & 21.27 & .000 \\
\hline $\begin{array}{l}\text { Negatif Davranışlardan } \\
\text { Kaçınma }\end{array}$ & B & $\mathrm{SE}(\mathrm{B})$ & $\beta$ & $t$ & $p$ & $\mathrm{R}^{2}$ & $\begin{array}{c}\text { Düz. } \\
\mathrm{R}^{2}\end{array}$ & $\begin{array}{c}\text { Anova } \\
\mathrm{f}\end{array}$ & $\begin{array}{c}\text { Anova } \\
\mathrm{p}\end{array}$ \\
\hline Kozmopolitan Sayg1 & .174 & .068 & .145 & 2.545 & $.000 * *$ & .021 & .018 & 6.48 & .011 \\
\hline Komüniteryan Sayg1 & -.039 & .074 & -.31 & -.533 & $.000 * *$ & .001 & -.002 & .28 & .594 \\
\hline Toplam Sayg1 & .122 & .091 & .077 & 1.337 & $.000 * *$ & .006 & .003 & 1.79 & .182 \\
\hline Toplam Sportmenlik & B & $\mathrm{SE}(\mathrm{B})$ & $\beta$ & $t$ & $p$ & $\mathrm{R}^{2}$ & $\begin{array}{l}\text { Düz. } \\
\mathrm{R}^{2}\end{array}$ & $\begin{array}{c}\text { Anova } \\
\mathrm{F}\end{array}$ & $\begin{array}{c}\text { Anova } \\
p\end{array}$ \\
\hline Kozmopolitan Sayg1 & .217 & .049 & .249 & 4.458 & $.000 * *$ & .062 & .059 & 19.88 & .000 \\
\hline Komüniteryan Sayg1 & .038 & .054 & .041 & .704 & $.000 * *$ & .002 & -.002 & .50 & 482 \\
\hline Toplam Sayg1 & .218 & .065 & .190 & 3.349 & $000 * *$ & .036 & .033 & 11.22 & .001 \\
\hline
\end{tabular}

Tablo 8'de bulgulara bakıldığında öğrencilerin toplam saygı düzeylerinin toplam sportmenlik davranışlarının yordayıcısı olduğu görülmüştür $\left(\mathrm{R}^{2}=.04, \mathrm{p}<.01\right)$. Alt boyutlara bakıldığında kozmapolitan saygının toplam sportmenlik davranışlarını $\left(\mathrm{R}^{2}=.06, \mathrm{p}<.01\right)$ anlamlı olarak yordadığı anlaşılmıştır. Ayrıca kozmopolitan saygının pozitif davranışlar sergileme boyutunu $\left(\mathrm{R}^{2}=.08, \mathrm{p}<.01\right)$ ve negatif davranışlardan kaçınma boyutunu $\left(\mathrm{R}^{2}=.02, \mathrm{p}<.01\right)$ anlamlı olarak yordadığı görülmüştür.

\section{TARTIŞMA VE SONUÇ}

Öğrencilerin sportmenlik davranışlarının negatif davranışlardan kaçınma boyutunda ve saygı düzeylerinin kozmopolitan saygı boyutunda kadınlar lehine anlamlı düzeyde farklılaştığı görülmüştür. Genel olarak ortaokul ve liseler için yapılan bazı çalışmalarda kızların erkeklere göre daha yüksek sportmenlik davranışlarına sahip oldukları görülmüştür (Esentürk, İlhan, \& Çelik 2015; Koç \& Tamer, 2016; Koç, 2017a; Koç, 2017b; Koç \& Karabudak, 2017; Koç \& Güllü, (2017); Tasi \& Fung, 2005). Saygı için yapılan bir çalışmada Kozmopolitan saygı ve toplam saygı kadınlarda anlamlı düzeyde daha yüksek çıkmıştır (Koç \& Yeniçeri, 2017). Toplumsal beklentiler kadınların erkeklere göre daha olumlu davranışlar sergilemesi yönündedir. Bu beklentiler doğrultusunda kadınların davranışlarını olumlu yönde düzenlemeye yönelik sosyal baskı oluşturabileceği düşünülmektedir.

Öğrencilerin sportmenlik davranışlarının sınıf düzeylerine göre negatif davranışlardan kaçınma ve toplam sportmenlik puanlarında 1 ve 4 . sınıflar lehine anlamlı düzeyde farklılaştığı 
görülmüştür. Öğrencilerin sportmenlik değerlerinde görülen düşüş ve artışların çeşitli sebepleri olabilmektedir. Sonuçlara derinlemesine bakıldığında 1. sınıftan itibaren düşme eğilimi göstermekte ve son sınıfta beklenmeyen bir şekilde yükselmektedir. Başka çalışmalarda elde edilen sonuçlar dikkate alındığında yaş ile birlikte sportmenlik davranışlarında azalma meydana gelmektedir (Esentürk, İlhan, \& Çelik 2015; Koç \& Tamer, 2016; Koç, 2017b; Koç \& Karabudak, 2017). Öğrencilerdeki bu düşme eğiliminin 4. sınıfa yaptıkları staj uygulamaları ve doğru öğretmenlik yapma sorumluluğu sonucunda sportmenlik davranışlarında düzelme eğilimi olarak kendini gösterdiği düşünülmektedir. 4. sınıfa gelen üniversite öğrencisi toplumda alacağı görev ve sorumlulukları çerçevesinde toplumun beklentileri doğrultusunda davranışlarda bulunma eğilimi geliştirebileceği düşünülmektedir. Bu düşüncenin test edilebilmesi için nitel çalışmalara ihtiyaç olduğu görülmüştür.

Ölçek puanları öğrencilerin üniversite takımlarında görev almalarına göre, aktif spor yapmalarına göre ve yaptıkları branş türlerine göre anlamlı düzeyde farklılaşmadığı görülmüştür. Benzer şekilde lise öğrencileri üzerinde yapılan bir çalışmada da sportmenlik davranışlarında okul takımlarında görev almanın etkisi görülmemiştir (Koç \& Tamer 2016). Spor bilimlerinde okuyan üniversite öğrencilerinde okul takımlarında görev almanın sportmenlik ve saygı düzeylerine olumlu ya da olumsuz etkisinin olmadığı sonucuna ulaşılmıştır. Araştırma sonuçlarının aksine Başaran ve ark. (2017), aktif spor yapan besyo öğrencilerin sportmenlik yönelimlerini aktif spor yapmayanlara göre anlamlı olarak düşük bulmuştur. Ortaokul ve liselere yapılan bazı çalışmalarda temassız sporlarla ilgilenen öğrencilerin sportmenlik davranışlarının (negatif davranışlardan kaçınma boyutunda) temaslı sporlarla ilgilenen öğrencilerden daha yüksek olduğu görülmüştür (Koç, 2017a; Koç, 2017b; Koç \& Karabudak, 2017). Saygı düzeyi için yapılan bir çalışmada da fiziksel teması olmayan sporlar ile ilgilenen lise öğrencilerin kozmopolitan sayg1 ve toplam sayg1 düzeylerinin fiziksel teması olan sporlarla ilgilenen öğrencilere göre anlamlı olarak daha iyi olduğu bulunmuştur (Koç ve Yeniçeri, 2017). Yapılan çalışmalarda ortaokul ve lise öğrencilerinde spor türünün davranışları etkilediği görülmüşken üniversitede okuyan spor bilimleri öğrencilerinde anlamlı farkın görülmemesi spor türünün etkisinin eğitimin de yardımıyla yaşla birlikte azalabileceğini akla getirmektedir. Öğrenciler spora başladığı ilk yıllarda yaptığı sporun doğasının etkisinde kalabilmektedir. Öğrenciler daha sonraki yıllarda aldıkları eğitimin etkisiyle olumsuz davranışlarını azaltabilmektedirler. 
Öğrencilerin toplam sportmenlik davranışlarıyla toplam saygı düzeyleri arasında pozitif yönde anlamlı ilişki bulunmuştur ( $\mathrm{r}=.19)$. Benzer şekilde lise öğrencileri üzerinde yapılan farklı bir çalışmada sportmenlik değerleri ile saygı değerleri arasında anlamlı ilişki bulunmuş fakat toplam sportmenlik değerleri ile toplam saygı düzeyleri arasındaki ilişki düzeyi daha yüksek $(\mathrm{r}=.31, \mathrm{p}<0.01)$ çıkmıştır.

Ölçekler arasında yapılan korelasyon analizinde doğrusal ilişki görüldüğünden saygı düzeyinin sportmenlik davranışını ne ölçüde yordadığına bakılmıştır. Elde edilen bulgulara bakıldığında öğrencilerin toplam saygı düzeylerinin toplam sportmenlik davranışlarının yordayıcısı olduğu görülmüsstür $\left(\mathrm{R}^{2}=.04, \mathrm{p}<.01\right)$. Özellikle kozmopolitan saygının pozitif sportmenlik davranışlar sergileme boyutunun $\% 8$ 'ini ve toplam sportmenlik davranışlarının da \% 6'sını yordadığı görülmüştür. Koç ve Yeniçeri (2017) ise çalışmalarında kozmopolitan saygının pozitif sportmenlik davranışlar sergileme boyutunun \% 11'ini ve toplam sportmenlik davranışlarının da \% 12'sini yordadığını tespit etmiştir. Bu sonuçlar Koç ve Yeniçeri'nin (2017) çalışmasıyla karşılaştırıldığında saygı düzeyinin sportmenliği yordama gücünün üniversite öğrencilerinde daha düşük olduğu anlaşılmıştır. Karşılaştırma yapılabilecek başka bir çalışmaya rastlanılmamıştır. Saygı davranışının sportmenlik tanımlaması içinde yer alması (Ellis, vd., 2004; Keating, 2007), saygı ile ilgili boyutun sportmenlik için geliştirilen ölçek içerisinde yer alması (Vallerand, vd., 1997) ve spor ortamında da Fair play davranışı için saygıya atıf yapılması (www.fifa.com, 2017) saygı davranışının sportmenlik davranışını etkilediği iddiasını güçlendirmektedir. Kozmopolitan saygının sportmenlikle olan ilişkisinin daha yüksek çıması sportmenlik davranışının evrensel bir değer olduğunu ön plana çıkarmıştır

Yapılan çalışma sonucunda sportmenlik davranışı ile saygı davranışı arasındaki ilişki ortaya konulmuştur. Özellikle kozmopolitan saygının sportmenlik davranışını anlamlı olarak yordadığı anlaşılmıştır. Spor bilimlerinde okuyan öğrencilerin saygı düzeylerini geliştirmeye yönelik etkinlikler uygulanmasının öğrencilerin sportmenlik davranışlarını geliştirmede faydalı olacağı düşünülmektedir.

Sportmenlik davranışları ile saygı düzeyleri arasındaki ilişkiyi ortaya koyan çalışmaların azlığı nedeni ile farklı gruplarla ve büyük ölçekli çalışmalar yapılması önerilmektedir. 
Koç, Y. ve Seçer, E. (2018). Spor bilimleri alanında eğitim gören üniversite öğrencilerinin sportmenlik davranışları ile saygı düzeyleri arasındaki ilişkinin incelenmesi. CBÜ Beden Ĕgitimi ve Spor Bilimleri Dergisi, 13(2), 247-259.

\section{KAYNAKLAR}

Arnold, P.J. (1998). Sport, ethics and education. London: Cassell.

Balçıkanlı, S. G. \& Yıldıran, İ. (2011). Profesyonel futbolcular sportmenlik yönelimleri ve empatik eğilim düzeyleri. Beden Ĕ̌itimi ve Spor Bilimleri Dergisi, IX(2), 49-56.

Başaran, Z., Erdoğan, R. B., Körmükçü, Y. \& Adalı, H. (2017). Beden eğitimi ve spor yüksekokulu öğrencilerinin fair-play anlayışlarının incelenmesi. Beden Eğitimi ve Spor Araştırmaları Dergisi (BESAD), 9(1), 35-43.

Demircan, Ş. (2017). Çocuklarda saygı eğitimi, Retrieved 31.05.2017 from http://www.mirathaber.com/seyma-demircancocuklarda-saygi-egitimi-20-373y.html

Ellis, G.D., Henderson, H.L., Paisley., Silverberg, K.E., \& Wells, M.S., (2004). Bringing sportsmanship back to your youth sports leagues, Parks \& Recreation, 39, 46-51.

Esentürk, O. K., İlhan E. L., \& Çelik, O. B. (2015). Examination of high school students' sportsmanlike conducts in physical education lessons according to some variability. Science, Movement and Health, 15(2, Supplement), 627-634.

FIFA, (2017). http://www.fifa.com/sustainability/news/y=2010/m=9/news=the-world-unites-fair-play-and-respect-1293362.html (Retrieved August 26, 2016).

Hendrick, C. Hendrick, S. S., \& Zacchilli, T. L. (2011). Respect and Love in Romantic Relationships, Acta De Investigación Psicológica, 1(2), 316-329.

Karasar, N. (2003).Bilimsel Araştırma Yöntemleri. Ankara: Nobel Yayın Dağıtım.

Keating, J. W. (2007). Sportsmanship as a moral category. In W. J. Morgan (Ed.), Ethics in Sport (2nd ed., pp. 141-152). Human Kinetics.

Koç, Y. (2013). Beden eğitimi dersi sportmenlik davranışı ölçeği (BEDSDÖ): Geçerlik ve güvenirlik çalışması. Erzincan Üniversitesi Ĕ̆itim Fakültesi Dergisi,15(1), 96-114.

Koç, Y. (2017a). A study on the relationship between high school students' physical education course sportsmanship behaviors and their patience levels. In M. Gammone, M. A. Icbay, \& H. Arslan (eds.), Recent Developments in Education (pp. 191200). Bialystok: E-BWN. Available from http://iassr2.org/rs/005.pdf.

Koç, Y. (2017b). Relationships between the physical education course sportsmanship behaviors with tendency to violence and empathetic ability. Journal of Education and Learning, 6(3), 169-180.

Koç, Y. \& Güllü, M. (2017). Research into sportspersonship behavior of high school students in physical education course in terms of some variables [In Turkish with English Abstract]. SPORMETRE, 15(1), 19-30.

Koc, Y. \& Karabudak, A. A. T. (2017). The relationship between sportsmanship level of secondary school students and their success regarding the religious culture and knowledge of ethics course. Educational Research and Reviews, 12(16), 754761. DOI: 10.5897/ERR2017.3316.

Koç, Y. \& Tamer, K. (2016). A study on the sportsmanship behaviors of female students in physical education course according to different variables. Nigde University Journal of Physical Education and Sport Sciences, 7(1), 16-27.

Koç, Y. \& Yeniçeri, S. (2017). An investigation of the relationship between sportsmanship behavior of students in physical education course and their respect level. Journal of Education and Training Studies, 5(8), 114-122. https://doi.org/10.11114/jets.v5i8.2477.

Loomans, D. \& Loomans, J. (2005). Çocuklara öz saygıyı ve değerleri öğretmenin 100 yolu (Birinci Bask1), İzmir: Ege-Meta Yayınları.

Pehlivan, Z. (2004). Fair-play kavramının geliştirilmesinde okul sporunun yeri ve önemi. SPORMETRE Beden Eğitimi ve Spor Bilimleri Dergisi, II (2),49-53.

Shields, D. L., \& Bredemeier, B. J. L. (1995). Character development and physical activity. Champaign, IL: Human Kinetics.

Tabachnick, B. G. \& Fidell, L.S. (2013). Using multivariate statistics (6 $6^{\text {th }}$ Edit.). Boston: Pearson.

Tsai, E., \& Fung, L. (2005). Sportspersonship in youth basketball and volleyball players. The Online Journal of Sport Psychology. 7(2), 37-46. Retrieved April 17, 2013, from http://www. athleticinsight.com/Vol7Iss2/ Sportspersonship.htm.

Topan, A. (2011). Ortaöğretim kurumlarında okullar arası futbol müsabakalarına katılan öğrencilerin fair play anlayışlarının kulüp deneyimlerine göre incelenmesi. Yayınlanmamış Yüksek lisans tezi, Gazi Üniversitesi, Ankara, Türkiye.

Türk, İ. (2009). Değerler eğitiminde sayg. Yüksek Lisans Tezi, Gaziosmanpaşa Üniversitesi Sosyal Bilimler Enstitüsü, Tokat, Türkiye.

Vallerand, R. J., Briere, N. M., Blanchard, C. M., \& Provencher, P. J. (1997). Development and validation of the multidimensional sportspersonship orientations scale. Journal of Sport \& Exercise Psychology, 19(2), $197-206$. https://doi.org/10.1123/jsep.19.2.197.

Yazıc1, A. \& Yazıc1, S. (2015). Saygı ölçeğinin geçerlik ve güvenirlik çalışması. International Periodical for the Languages, Literature and History of Turkish or Turkic, 10(4), 769-780. Retrieved 4 January 2016 from http://dx.doi.org/10.7827/TurkishStudies.9079. 